\title{
Godfray Review, Bovine Tb, Perturbed Badgers or Problem Herds?
}

\author{
Martin Hancox* \\ 17 Nouncells Cross, Stroud, GL5 1PT, UK \\ Submission: December 18, 2018; Published: January 04, 2019 \\ *Corresponding author: Martin Hancox, 17 Nouncells Cross, Stroud, GL5 1PT, UK
}

\section{Introduction}

GB's textbook Area Eradication cattle TB scheme shrank TB from nationwide, down to two dozen "intractable" southwest islands, c. 1000 sq.km., of TB by the 1970s, without any badger culls! The obstacle to eradicating TB in these last hotspots, was a small number of "problem herds" [1]. But, alas, oh what a tangled web MAFF wove back then, when they mistakenly blamed Badgers as being "the main cause of the spread of the scatter of unconfirmed cattle TB herd breakdowns ". The idea that there is a self-sustaining reservoir of "endemic" badger TB, as in the Wood Chester Park high density population, which is the engine generating the scatter of new breakdowns, as well as re-infection of TB, in "Problem herds", with recurrent or ongoing chronic TB, was endorsed, by the ISG 2007 report on the RBCT, or Randomized Badger culling Trial, and sadly endorsed by Woodroffe [2,3], and the Godfray and latest 13th November 2018, 138 page review.

A new generation of farmers, vets and indeed veterinary epidemiologists within DEFRA, DAFM, DAERA in England, Wales, Eire and Ulster, will be surprised to re-discover that bovines are the natural self-sustaining host of bovine TB which is an infectious respiratory bronchopneumonia. It has been overlooked that the spread is a via a seemingly unconnected four step progression: - 1. it takes about a year for the initial alveolar droplet infection site in the lung to metastasise through, granuloma, then NVL No Visible microscopic lesions, to the more infectious VL Visible Lesion stage, then cavitation and spread to liver, uterus, mammary glands, etc.; within herd aerosol spread occurs readily via prolonged close "contact "in shared airspaces such as barns or milking parlours; dispersal of these new cases to a scatter of mostly local herds, by cattle movements, currently new breakdowns are $60 \%$ VL Confirmed and $40 \%$ NVL Unconfirmed. OTF-S, AND OTF-W; $95 \%$ of "normal" breakdowns test clear with 1-2, 60-day or SIT (Short Interval Tests), but as was known back in 1900 at the start of many TB national TB Eradication schemes, the SICTT Skin test misses early and late TB cases, so these are the usual cause of recrudescence in the $5 \%$ of Problem Herds. Latency and Energy, about a third of bad breakdowns have recurrent TB within 18-36 months, due to latent TB.

And in about a third, normal immunosuppression which means the calf is not rejected as foreign protein during pregnancy means cows will test "false negative", particularly peri-natally. And a significant minority of elderly cows fail to restore the immune response post-calving, so become permanently "anergic", the cause of ongoing chronic $\mathrm{TB}$, but these active spreader skin-test non-reactors can now be found easily using new tests IDEXX \& Actiphage, as in the textbook Sussex herd below [4] Cattle schemes in the past in national herd surveillance, did not bother to test cattle under 6 months old since they would not be at the reactor stage. So, pity England and Wales are now trying 6 monthly testing, an unnecessary pointless burden of farmers. Shock news, from CVERA [5] in Eire. They present a very valuable map, of the starburst scatter of cattle movements, from kernel hotspots, with a significant number of chronic herds, responsible for the local scatter of new herd breakdowns [6]. A clonal expansion of cattle DNA Spoligotype "home ranges". In 2016, 1.3 million cattle movements, of 6.7 million individual cattle, over 46 million kilometers! In England some 20 million cattle movements / a, and test only $49 \%$ accurate. no wonder TB spreads within the cattle population.

\section{Perturbed Badgers Fact or Fiction}

The "highly complex and emotive" Great Badgers and Bovine TB Debate, has rumbled back and forth for nearly 50 years. Ever since the "first" 3 official TB badgers in Glos. and Glamorgan in 1971, Ulster/ Eire 1974, 1975. But the idea that badgers are the cause of $50 \%$ of unconfirmed breakdowns unbelievably rests on two very simple costly mistakes. No-one seems to have realized, as explained above, that NVL reactors are merely newly infected cases (see above), and the precursors of the VL stage. So, MAFF vets ruled out the obvious within herd spread and wrongly assumed that these cases were "false positive", and did not have TB, and so wrongly, must have caught it from badgers [7]. DEFRA's 2015 consultation on post-movement testing finally 
re-discovered ALL reactors DO have TB, caught in the previous herd breakdown [8]. So NVL/Unconfirmed/OTF-S are no longer distinguished from VL/Confirmed/OTF-W reactors, DEFRA statistics now class herds as OTF or Non-OTF. Pre-and Postmovement testing from April 2016 stops spread from HRA to Edge \& LRA areas.

N.B. All the scatter of new unconfirmed breakdowns supposedly "Due to badgers" are embarrassingly simply due to unconfirmed reactors from the last breakdown. Nothing to do with badgers whatsoever. So, badger culls must be unlawful under the 1992 Badgers Act, since they will never stop the spread of bovine TB by bovines! No-one in 50 years has realistically explained how badgers might give cattle a respiratory lung "pneumonia", particularly as eight badger-cattle contact studies found that badgers avoid cattle at pasture, in farmyards and in barns.

The first "result" in the RBCT Randomized Badger Culling Trial, was an unexpected rise in cattle $\mathrm{TB}$, in reactive cull areas and in the buffer ring outside proactive cull areas. The ISG leapt to the conclusion that it must be due to the cull, so invented the idea that badgers "perturbed" by the cull must be meeting more badgers and more cows and increased the spread of TB accordingly. It is extremely unfortunate that badger cull policy in England, Wales, Eire and Ulster is now based on the flawed RBCT/ ISG/Godfray/Woodroffe [2] model. Supposedly culls will halve cattle TB, if over a big enough area, such that the detrimental initial perturbation rise in the outside buffer ring, is outweighed by the beneficial drop inside proactive cull areas. This fake science has been repeated in two dozen peer reviewed journals, but unbelievably, no-one has noticed that there WAS NO CULL in the outside buffer ring, so no perturbed badgers. And the rise in reactive cull areas happened before the cull, so it was not due to perturbed badgers either. Much simpler, the dramatic rise in all 30 trial areas and all 30 buffer rings, was simply the accumulation of two years' worth of reactors, due to lack of testing during foot \& mouth 2001. With incidentally a $70 \%$ TB spillover TO badgers. A similar rise in Wales and Ulster, without badger culls. But no rise in Eire since they did not suspend testing during FMD. The actual result of the RBCT was zero effect on unconfirmed breakdowns, since they are not due to badgers after all. And Lefevre's 2005 study found no difference between reactive versus no cull areas in accumulated breakdowns 356 vs 358, it should have been 175 if culls "halved" cattle TB! [9].

So, the badger cull Perturbation rise is pure fantasy. And the decreases in cattle TB in the RBCT, and the APHA [10], 2018 reports are simply due to the variable effectiveness of intensive cattle testing. Donnelly [11] in fact downgraded the badger contribution to cattle TB from 54, to 5.7, or even $3.7 \%$ with a generous C. I. of ZERO to $100 \%$. So, badgers have never been the problem in the first place. There has never been any selfsustaining reservoir of badger TB, even in Woodchester Park, micro-pockets of spillover TB die out rapidly [12]. During the
RBCT there were only 1515 TB badgers, out of 11,000 culled from 1900 sq.km., and under 200 super-excretory badgers which might have been a risk to other badgers or cattle. Concurrently c. 130,000 cattle reactors. Similarly, the reduction in cattle in Irish culls, was due to cattle controls, not the removal of a mere 141 TB badgers from 550 sq.km. in Offaly, 258 from 850 sq.km in the Four Areas trial, and 176 TB badgers from 1750 sq.km. in Laois [13].

So, badger culls or vaccination or even fertility control schemes absurdly suggested in Godfray are a wonderfully insane solution to a non-existent problem. Woodroffe also advocates vaccination, but Welsh farmers are perfectly aware the IAA scheme didn't work. The Killer ton Estate vaccination did not stop 6 breakdowns in 2014. And the latest Kilkenny study from Eire also discredits any such scheme. Aznar [14] found that there were 55 TB badgers out of 239 unvaccinated badgers 23.3 $\%$, and 40 / $201,19.9 \%$ vaccinated ones, so it does not stop most badgers from catching TB from the next herd breakdown. Vaccination had nil effect on badger "infectivity", which is already extremely low.

\section{Problem Herds}

Reports on the epidemiological misunderstandings and realities in the difficulties of TB control with imperfect tests, are clearly exposed in the sad case of Nick Adames, with chronic TB since March in his dairy herd, near Arundel, East Sussex [15]. Some 100 cows, plus 124 followers, "Clear" for 19 years, and run as a "closed" herd. No sign of any TB badgers in that time presumably. The original study of the new Sussex "hotspot" back in 1986, found only 34 TB Sussex badgers out of 1319 sampled, with the new spillover Spoligotype [16]. So, whilst he expresses concern at the large volume of cattle imported into Edge areas from the HRA, and the only $49 \%$ sensitivity, of the SICTT test, this is bound to mean TB cases slipping through the net even with pre- and post-movement tests. Twenty million cattle movements/ a. In fact, this "Brighton" hotspot, only has some 9 breakdowns/ a, and started back in the 1970s, with an unusual Irish Spoligotype, SBO 273. Rather like the new Cumbria hotspot, Type 17; where there were only 3 TB badgers out of 35 culled, so hard to believe this justifies LRA culls this year? And Bennett [17] found just 20 TB badgers out of 94 sampled, in Cheshire.

DEFRA's consultation was puzzled that the hotspot does not expand, but there is little or no export of cattle to low intensity nearby cattle counties such as hampshire, west sussex, surrey, kent; unlike frequent movements from Cheshire or Shropshire. A third of Gopal's [18] north-east re-stocking breakdowns came from one problem Cheshire herd. And most of local cattle movements are within this hotspot. So, a breakdown some $2-3 \mathrm{~km}$ away, is the most likely source of his breakdown, as with foot and mouth, infectivity probably came in via slurry on the wheels of vehicles, driving freely farm to farm around in the hotspot, post vans, milk and feed lorries. 
Interesting that DEFRA, no longer bother with culturing samples from NVL No Visible Lesion reactors. In fact, as the SICTT skin test is $99.99 \%$ specific, only 1 in 5000 reactors will not have TB, i.e. be truly "False Positive". So, sadly 2 NVLs, and 3 IRs Inconclusive reactors in the initial breakdown in March, all infected. And two Irish studies found that $20 \%$ of NVL reactors were sputum positive, so still spreading respiratory TB within the herd $[19,20]$. So, IRs at all 360 -day SIT retests since were newly infected cases, and clear at second or third retest owing to latent infection. It is astonishing that the significance of IRs has been misunderstood in studies in England, Wales and Eire. They ought to be removed as TB positive since $25-30 \%$ are likely to reappear as good reactors 3-7 years later. A botched compromise, putting them under a lifetime ban from them moving from the herd, and more costly long term not removing IRs. Most farmers know that about a third of bad breakdowns will have recurrence within 18-36 months. And interestingly, herds with longer term chronic TB, up to 16 years plus, may only have 4-5 new cases at most SITS, but 40 or more if the SIT is roughly a year after the last over-wintering in barn high transmission risk period [2123].

Clearly such chronic herds have an elderly active spreader cow, which has become a non-reactor to the skin test, so the simple solution now available is to use IDEXX Ab antibody test for this anergic cow, with ACTIPHAGE M. bovis detection to round up new cases more rapidly. The Devon Gatcomb herd went clear using these tests, no badger cull needed, and not re-infected by badgers even though spillover to c. $25 \%$ TB + [4]. A pity Wales have not until the recent Save Me Trust Gower study, tried this, given the 60 chronic herds there. The $2017 £ 380,000$ study of chronic herd cull licenses found just 7 TB badgers out of 37 sampled in 2 farms. Nick's herd would be a prime test case for using IFN, or the new ACTIPHAGE and IDEXX antibody tests, to find such poorly sensitized reactors. And No, no need to depopulate as in the past, and mistakenly advocated by Godfray.

Interesting to recall another chronic herd Sussex case, David Butler near Uckfield, who was prosecuted in 2015, for movement of stock between sub-holdings, even from Dorset, and failure to isolate reactors, and properly disinfect the premises: the common-sense cattle risk factors for perpetuating the problem!

\section{References}

1. Richards R (1972) TB in West Cornwall, MAFF.

2. https://www.zsl.org/blogs/science/what-does-the-godfray-reviewmean-for-badgers.

3. https://www.zsl.org/sites/default/files/media/2018-09/ZSL Eradicating_TB_Report_final_24SEP18.PDF.

4. http://www.pbdbio.com/news/actiphage-is-test-farmers-want-touse-in-godfray-tb-review

5. https://www.farmersjournal.ie/watch-46-million-kilometres-worthof-cattle-movements-in-ireland-407652

6. Doyle (2016) chronic herds.

7. Zuckerman S (1980) Badgers, cattle and tuberculosis, MAFF.

8. Francis J (1947) Bovine tuberculosis, Staples Press, Europe.

9. ISG (2007) Final report of Independent Scientific Group on RBCT.

10. https://www.gov.uk/government/uploads/system/uploads/ attachment_data/643492/tb-badger-control-third-year-analysis.pdf

11. http://currents.plos.org/outbreaks/article/the-contribution-ofbadgers-to-cattle-tb-incidence $3.7 \% \mathrm{CI}$ zero- $100 \%$

12. Delahay R (2000) Woodchester badgers, J an Eco 69: 428.

13. Roper T (2010) Badger, New Naturalist.

14. Aznar I (2018) Kilkenny vaccination, quantification of effects.

15. Farmers Weekly (2018) Nick Adames, chronic herd Sussex.

16. Wilesmith J (1986) TB in Sussex, J Hygiene, 97: 1.

17. https://www.nature.com/articles/s41598-018-35652-5

18. Gopal (2006) northeast restocking, Vet Rec 159: 265

19. McIlroy J (1986) cattle lesions, Vet Rec 118: 718.

20. Neil S (1988) cattle lesions, Vet Rec 122: 184.

21. https://www.bbc.co.uk/news/science-environment-46187230

22. Death of Debate, and Cows give badgers TB, Vet Rec Ecologist.

23. Langton T, McGill I (2018) Effectiveness of culls.

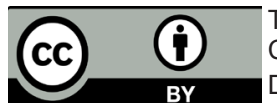

This work is licensed under Creative Commons Attribution 4.0 License DOI: 10.19080/JDVS.2019.08.555755

Your next submission with Juniper Publishers
will reach you the below assets
- Quality Editorial service
- Swift Peer Review
- Reprints availability
- E-prints Service
- Manuscript Podcast for convenient understanding
- Global attainment for your research
- Manuscript accessibility in different formats
( Pdf, E-pub, Full Text, Audio)
- Unceasing customer service
Track the below URL for one-step submission
https://juniperpublishers.com/online-submission.php

